\title{
Funciones atenuadoras del conjunto léxico- discursivo no sé en un corpus oral del noreste de méxico, Es.Var.Atenuación
}

MITIGATING FUNCTIONS OF THE LEXICAL-DISCURSIVE UNIT NO SÉ IN AN ORAL CORPUS OF NORTHEASTERN MEXICO, ES.VAR.ATENUACIÓN

\author{
Armando González Salinas \\ Facultad de Filosofía y Letras, UANL
}

\section{Resumen}

\begin{abstract}
Se elabora y describe una primera fase exploratoria sobre el uso de la frase léxico-discursiva no sé como marcador de atenuación en el corpus Monterrey PRESEEA y un corpus para ES.VAR.ATENUACIÓN Monterrey. Se sigue la clasificación original por forma y función con 9 entrevistas: 4 hombres y 5 mujeres, de edad y escolaridad coincidente. Se compara y contrasta la variedad diafásica - estructura donde se encuentra- a partir de las dimensiones diatópica y diastrática de esta frase en un corpus oral del Noreste de México (Monterrey). Se basa en la propuesta teórico-metodológica de Briz y Albelda (2013). Se busca la intención atenuadora como minimización de la fuerza ilocutiva y la desfocalización (Aijmer, 2002) de los participantes en la enunciación. Es una táctica intencional en la efectividad/eficacia del discurso para propósitos de la interacción contextual (Briz y Albelda 2013: 292). Este acercamiento está relacionado con las propuestas de otros investigadores: Caffi (1999), Fraser (1980, 1990); Meyer-Hermann (1988); Haverkate (1994) y Briz (1995, 1998, 2005 y 2007).
\end{abstract}

PALABRAS CLAVE: atenuación, marcador discursivo no sé, conversación espontánea. 


\section{Abstract}

This is an exploratory phase of the use of no sé (I do not know) as a mitigation marker in Monterrey PRESEEA corpus and ES.VAR.ATENUACIÓN Monterrey, another corpus. It follows the original classification by form and function with nine interviews: four men and five women, of coincident age and schooling. The diaphasic variety, structure where it shows, compares to its diatopic and diastratic dimensions, in an oral corpus of Northeastern Mexico: Monterrey. Based on Briz and Albelda's (2013) theoretical-methodological proposal. We search for the mitigating intention, viewed as a minimization of the illocutionary force and the 'defocusing' defocalization (Aijmer, 2002) in participants' enunciation. It is an intentional tactic on the effectiveness / efficiency of discourse for contextual interaction purposes (Briz y Albelda 2013: 292). This approach is related to proposals from other researchers such as Caffi (1999), Fraser (1980, 1990); Meyer-Hermann (1988); Haverkate (1994) y Briz (1995, 1998, 2005 y 2007).

KEYWORDS: mitigation, discourse marker no sé, spontaneous conversation

\section{$1 \quad$ INTRODUCCIÓN $^{1}$}

Dentro del extenso campo de estudios de la atenuación que se aplican al discurso oral en variedades del español de España y América, se encuentra el proyecto para la observación de la actividad atenuadora que dirige Marta Albelda en la Universidad de Valencia: ES.VAR.ATENUACIÓN. Se trata de una propuesta teórico-metodológica que se aplica, en este caso, para el estudio del español en Monterrey, México, específicamente en lo que se refiere al empleo de la frase léxico-discursiva no sé. Se observa y analiza su empleo tal y como se detecta al escuchar las grabaciones ocultas que conforman el corpus de este estudio. Es importante mencionar que la búsqueda de las apariciones que se dieron, tiene como antecedente un estudio preliminar del mismo marcador atenuador en el corpus MonterreyPRESEEA, (González Salinas, 2013), en el que se basa y del que parte este trabajo investigativo. Para aquel trabajo se recurrió a la ficha de codificación PRESEEA (Albelda, Cestero, 2010, Albelda, Briz, Cestero, 2014), en la Modalidad B (Cestero, Rodríguez, 2014), y para este además a la Ficha de Información Complementaria para ES.VAR.ATENUACIÓNMonterrey, como es natural suponer, todo estudio de marcadores discursivos se inicia al tomar en cuenta las características socio-culturales que el objeto de estudio representa; con esto en perspectiva, el uso del no sé como indicador de fingimiento de ignorancia, principalmente, por tanto vehículo atenuador, se observa en contextos conversacionales que, si bien se pueden asemejar al uso que se le da en otros países hispanohablantes, cuenta con rasgos específicos de la variedad dialectal de que se trate, el español de Monterrey en este caso. Esto presupone que se distingan las diferentes manifestaciones de uso, que en esta fase exploratoria nos interesa realizar, y cuyo amplio objetivo general a mediano y corto plazo pretende comparar y

\footnotetext{
${ }^{1}$ Esta investigación se adscribe al proyecto «La atenuación pragmática en el español hablado: su variación diafásica y diatópica» (Ministerio de Economía y Competitividad de España, ref. FFI2013-40905-P).
} 
contrastar los dos corpus en cuestión (PRESEEA y ES.VAR.ATENUACIÓN) ambos de la misma variedad geográfica: Monterrey.

Con esta intención, se sigue la ficha de análisis que como instrumento teórico metodológico ha sido diseñada para este efecto (Albelda et alii, 2014). Dado que se trata de un elemento discursivo en particular, se encuentran, de entrada, algunas diferencias entre ambos análisis, por tanto, hay aspectos del proyecto Monterrey- PRESEEA que no se consideraron dentro del análisis de ES.VAR.ATENUACIÓN-Monterrey, como se describe más adelante.

\section{PRESEEA - ES.VAR.ATENUACIÓN}

En términos generales, tanto en el corpus PRESEEA como en el corpus ES.VAR.ATENUACIÓN, ambos de la variedad del español de Monterrey, la intención pragmática es asertiva, lo que corresponde a una descripción del estado actual de la realidad. En el primer corpus, se trata de un diálogo entrevista que supone la participación de un entrevistador quien, de una manera (semi) controlada va guiando / enfocando la conversación con la intención de obtener la información deseada, la variación diafásica de una entrevista. El informe está completamente de acuerdo y consiente de que está siendo grabado, lo cual le hace estar atento a lo que dice en forma y contenido. Esto también le permite reparar o volver a decir lo que piensa que "debe" ser más "correcto". Las características del segundo corpus se describen más adelante.El marcador discursivo no sé, corpus Monterrey-PRESEEA

De este corpus se seleccionó el Grupo 1, que se identifica por tres variables: 1) edad, 20-34 años, 2) género: 18 hombres y 18 mujeres, y 3) estrato socioeducativo: escolaridad mínima, técnica/secundaria, y con estudios de licenciatura, en proceso o terminados.

En el discurso de los diferentes subgrupos del Grupo 1, se detectó el uso constante del no sé, tanto para indicar ignorancia o falta de conocimiento, así como para cumplir la función de atenuante con el fin de aligerar lo que se dice, para no proporcionar datos exactos, o para no comprometerse, además de las otras muestras del mismo no sé con otras intenciones ilocutivas. La frase no sé puede incluso clasificarse como estrategia atenuante de relativización o indeterminación de lo expresado en el caso de una entrevista en la que el entrevistador induce al informante para que dé información que requiere. En este caso el significado de la frase no sé es la negación en primera persona del verbo saber, pero dado que se identifica que actúa como atenuante en el discurso entrevista, se pierde un poco del significado original de la frase, se vuelve un poco vacía, y se utiliza de forma que el hablante se desvía un poco de la aserción que realiza, o divaga ligeramente antes de declarar algo para evitar comprometerse.

Para realizar el análisis en este corpus, se definieron dos tipos de criterios para la clasificación del no sé, como sigue: 


\begin{tabular}{|c|c|}
\hline Criterios formales: & Criterios funcionales: \\
\hline $\begin{array}{c}\text { no sé + qué, cómo, cuándo, (en) dónde, por qué, cuál } \\
\text { (es) cuanto(a) (os) (as) }\end{array}$ & Atenuación \\
\hline no sé + si + verbo en indicativo o en subjuntivo & Atenuación + cortesía \\
\hline no sé - ignorancia per se & Función fática \\
\hline
\end{tabular}

Tabla 1. Criterios formales y funcionales para la clasificación del no sé

Los criterios formales se perciben como distribucionales con respecto a las estructuras adyacentes del marcador discursivo en cuestión, y la relación semántica subyacente. Su codificación, explicación y análisis son parte de la fase subsecuente del estudio del no sé en estas circunstancias léxico-estructurales. Por otro lado, los criterios funcionales se utilizan para describir y señalar el propósito, la intencionalidad, e incluso relación de la estructura léxica al emplearse como atenuante en la expresión verbal de un acto comunicativo que conlleva la participación tanto de quien enuncia como de quien escucha. Este es el primer acercamiento que se estudia en 2012-2014.

\section{EL MARCADOR DISCURSIVO NO SÉ, CORPUS ES.VAR.ATENUACIÓN-MONTERREY}

La intención pragmático-atenuadora consiste en la minimización de la fuerza ilocutiva y la desfocalización de los participantes en la enunciación. Para Aijmer, (2002) en la desfocalización se advierte un efecto de comunión íntima, de falta de precisión del informante al emplear no sé en la conversación. La desfocalización es una denominación de impersonalidad eventual genérica, es una táctica de distanciamiento que es manejada por el hablante para reducir o minimizar su propio papel o el del oyente en lo descrito (Haverkate, 1994: 131). La atenuación en este corpus, se observa como una táctica intencional que se manifiesta a través de la efectividad y la eficacia del discurso, para alcanzar los propósitos de y en la interacción, un recurso discursivo que solamente el contexto lo determina (Briz y Albelda, 2013: 292).

Es a partir de aquí donde se comienzan a identificar los factores que influyen en el análisis discursivo de la atenuación que precisa la función general de lo atenuante en el discurso, al considerar el contexto para poder detectar si la función requiere tener en cuenta los actos o las intervenciones anteriores, así como las posteriores. De esta manera se identifica cuál es el marcador atenuante y qué es lo que atenúa, variación diafásica, o contextual, de una conversación coloquial. Los cuatro rasgos principales en los que se basa la descripción del empleo del no sé son:

Los cuatro principales rasgos en los que se basa la descripción del empleo del no sé son: 
Se analiza el conjunto léxico-discursivo no sé como marcador de atenuación, bajo las condiciones que marcan los instrumentos para definirlo y concentrarlo en este corpus en su primera fase exploratoria, esto en el sentido de encontrarse en pleno desarrollo (ver datos de aplicación en anexo 1). Se han detectado y registrado102 muestras de las cuales 90 se han clasificado (ver muestra en anexo 2) dentro de los parámetros de búsqueda que son los criterios formales y funcionales que ya se han mencionado.

Se han escogido nueve conversaciones de este corpus oral del noreste de México: Monterrey, con la participación de 4 hombres y 5 mujeres, quienes se encuentran dentro del mismo rango de edades, la mayoría entre 28-36 años de edad, y con el mismo nivel de escolaridad. En tres de las grabaciones transcritas el rango de edad se extiende a mayores de 45 y hasta 68 años de edad, ya que quien las llevó a cabo lo hizo con su papá y su mamá en compañía de sus amigos. Los participantes que intervienen en las grabaciones ocultas son por lo menos dos y hasta tres o más, lo cual presupone una variedad de voces e intervenciones que hacen un tanto difícil la tarea de transcribir lo que dicen. Actualmente se está trabajando en la detección de cuántos son los hablantes realmente, y cuántas sus intervenciones concretas, dentro de lo posible, ya que por ser un discurso oral y el ambiente es informal, es fácil precisar con exactitud la identificación de cada uno de ellos sólo por las voces de hombre y/o mujer, que en algunos casos pueden confundirse. Para efectos de las muestras mismas, se identifican con una $P$ (participante) y número de intervención conforme interactúa, y en el orden de la conversación (P1, P2, P3, P4), sin que esto signifique que es el mismo participante 1 en todas las muestras. Se identifican los participantes con $\mathrm{m}$ (masculino) y $\mathrm{f}$ (femenino) con relativa certeza. En cuanto a la responsable de la grabación oculta se identifica en las grabaciones porque la llaman por su nombre, pero se le considera una participante más (P1, 2, 3, 4). Los temas de conversación, en general, se van dando conforme fluye la "plática" espontánea.

Se realizaron conversaciones que fueron hechas con grabación oculta con el fin de explorar la forma espontánea de la interacción en un marco social informal en donde los responsables de llevarla a cabo les pareció oportuno. Todas las muestras cuentan con autorización con firma de quienes aceptaron, hubo quienes lo rechazaron.

Se encontraron las siguientes manifestaciones de no sé y sus indicadores:

\begin{tabular}{|l|l|}
\hline $\begin{array}{l}\text { no sé + qué, cómo, cuándo, (en) dónde, } \\
\text { por qué, cuál (es) cuanto(a) (os) (as) }\end{array}$ & Atenuación \\
\hline $\begin{array}{l}\text { no sé + si + verbo en indicativo o en } \\
\text { subjuntivo }\end{array}$ & Atenuación + Cortesía \\
\hline no sé- ignorancia per se & Función fática (poco) \\
\hline
\end{tabular}

Tabla 2. El marcador discursivo no sé corpus Es.Var.Atenuación-Monterrey 
Todos estos marcadores corresponden a lo que se encontró en el corpus MonterreyPRESEEA. Sin embargo hay que observar que las conversaciones de Es.Var.AtenuaciónMonterrey se realizaron con grabadora oculta, de forma espontánea, en un marco socializador donde la relación de los participantes es de amigos, familiares o colegas cercanos. Como consecuencia, no se le da el mismo uso al no sé, ya que no existe esa predisposición del 'bien decir' como en una entrevista (semi) dirigida, que es el caso del otro corpus. Como se anticipó, para Aijmer (2002) en la desfocalización se advierte un efecto de comunión íntima, de falta de precisión del informante al emplear 'no sé' en la conversación, lo cual es señal de esa comunión, incluso en el campo de lo implícito, que sólo permite darse por la afinidad que existe entre los interlocutores.

"Vagueness and hedges are pervasive features in conversation ... the fact that speakers are friends and colleagues with shared interests obviates the need for explicitness" (Aijmer, 2002:111).

En cuanto a la variación diatópica: ES.VAR.ATENUACIÓN-Monterrey, la relación vivencial entre los participantes, como ya se mencionó anteriormente, es de amigos, colegas conocidos y familiares, lo que permite una conversación más fluida y sin limitaciones, ya que como se encuentran en un ambiente de confianza, el tono se torna un tanto despreocupado y totalmente informal, y es por esta misma razón, que no se sigue un tema específico y la conversación va cambiando de un tema a otro rápida y espontáneamente. Los factores que se toman en cuenta para el análisis discursivo de la atenuación son:

Primero se determina la función general de lo atenuante en el discurso, es decir, el contexto para así poder juzgar si la función requiere considerar los actos o las intervenciones anteriores y/o también las posteriores. Segundo, se determina cuál es el marcador atenuante y qué es lo que atenúa, lo cual aquí ya se encuentra localizado.

Dentro de los procedimientos lingüísticos (y no lingüísticos) empleados, se omitieron algunos que no coincidían con los parámetros que se utilizan para el estudio de la partícula del no sé y se comenzó con el empleo de verbos, construcciones verbales, así como de partículas discursivas con valor modal que expresan opiniones en forma de duda o probabilidad; se encuentra así, que él no sé funge en su mayoría como partícula discursiva que expresa las opiniones en forma de duda o probabilidad y en el resto de los casos no se encontraron verbos, $u$ otras partículas ni construcciones que expresan las opiniones en forma de duda o probabilidad. Por ejemplo, el participante 3 dice:

(1)

P3: lestábamos platicando / no sé cómo salió el tema de Ricardo Arjona /y que él lo catalogaba como un trovador/

\footnotetext{
${ }^{2}$ La vaguedad y las vallas /cercas son rasgos (pre) dominantes en la conversación... el hecho de que los hablantes son amigos y colegas con intereses compartidos evita la necesidad de ser explícito. Traducción propia.
} 
Corpus Es.Var.Atenuación-Monterrey, muestra 6

El punto 2.7 de la ficha (ver Anexo 1), el empleo de verbos, construcciones verbales y partículas discursivas que expresan fingimiento de incertidumbre, de incompetencia o de ignorancia sobre la capacidad de una persona para realizar algo. De esto resulta que en gran parte de los contextos atenuados no hay verbos, pero, sí existen partículas discursivas que expresan fingimiento de incertidumbre, de incompetencia o de ignorancia. Este patrón, de incertidumbre e ignorancia es el que predomina durante todo el estudio, ya que como a los participantes de las conversaciones no se les informó que sus conversaciones estaban siendo grabadas para el propósito de este estudio, se advierte una manera más informal y despreocupada en el discurso del hablante y su interacción con los demás. Se pudo encontrar que en algunas ocasiones el no sé es utilizado como un movimiento de reformulación a partir del acto propio del hablante, con lo que trata de matizar o corregir lo dicho. Por ejemplo:

(2)

...vi un video que pusieron en la- en el Facebook donde está / no sé siii / alguien / no lo escuché si fue cuando- declararon / ya como candidato a este cuate/

Corpus Es.Var.Atenuación-Monterrey, muestra 3

En lo que corresponde al número de atenuantes empleados por acto, por lo general solo se utilizaba una táctica por acto, pero en términos generales, se localizan tres diferentes números de tácticas o procedimientos de atenuación empleados que tienen que ver con el tema en cuestión.

Respecto a la posición discursiva de la atenuante en el miembro discursivo al que afecta, una vez que el segmento atenuado sea identificado ocurren las tres posiciones del segmento atenuante y su relación: la inicial, intermedia y final, además de las de integración, en caso de que el atenuante se encuentre dentro de la estructura proposicional. Tales son los casos encontrados dentro del estudio, donde se puede observar que el no sé se encuentra tanto en la posición intermedia, ya sea dentro de un movimiento de reformulación o una rectificación, como en las Muestras 3 y 6, o en posición inicial, o final en función del mismo atenuante, o aun en distintas posiciones.

La atenuación se produce dentro de diferentes secuencias, ya sea argumentativa, descriptiva, narrativa o fática. Pero, debido a que los textos a analizar para este proyecto son conversacionales y de habla más coloquial, fue difícil dividirlas por secuencias ya que por lo general las conversaciones cotidianas no siguen un parámetro específico y tienden a cambiar rápido, por lo que, para valorar este tipo de textos de intervención a intervención, se debe identificar primero qué tipo de texto es el que domina la intervención, puesto que el propósito de las nueve conversaciones analizadas era de las relaciones sociales, por lo que se advierten turnos rápidos y breves entre los participantes y con un habla informal y de temática cotidiana.

Se encontró que la intervención que se utiliza es la fático-expositiva ya que lo propio de un discurso de acuerdo con ésta es el hablar de temas sociales y el mantenimiento o incremento de las relaciones sociales. Por esto mismo, se observa que el contenido de lo dicho, en relación 
con las imágenes de las personas, se atenúa, aunque el contenido no tenga relación con la imagen de los hablantes, cuando se trate de un contenido negativo por alguno de ellos, o un participante que no esté presente en la interacción al momento, así como cuando el contenido es positivo o halagador.

En seguida se presentan muestras de lo que se lleva recolectado hasta ahora y que consiste más en una recopilación de señales de atenuación a través de manifestaciones de no sé y su cuantificación en gráficas. Esto se puede observar en las tablas correspondientes que se ajustan a lo que se puede encontrar en el Anexo 1, que muestra la selección de los recursos de atenuación que se detectaron para este corpus. No obstante, cabe señalar la importancia que hasta ahora muestran los resultados ya que, a pesar de estar sin terminar, apuntan hacia un recuento sobresaliente tanto en su análisis descriptivo como estadístico

\subsection{Función general del atenuante en el discurso}

En el caso de las conversaciones que se analizaron en este proyecto, se encontró que las principales funciones de la atenuante eran para la autoprotección del yo, sin que exista un interés en la imagen, la autoprotección del yo para beneficio del yo mismo, protección del yotú, es decir, proteger de que no surja un problema con el interlocutor y en tan solo un caso, se dio la reparación del yo-tú, es decir cuando el locutor daña, o cree dañar, la imagen del locutor y trata de remediarlo:

\begin{tabular}{|l|l|}
\hline $\begin{array}{l}\text { 0. Velar por sí mismo, reduciendo el } \\
\text { compromiso del hablante }\end{array}$ & 59 \\
\hline $\begin{array}{l}\text { 1. Velar por sí mismo, auto-protegiéndose por lo } \\
\text { dicho o por lo hecho }\end{array}$ & 27 \\
\hline $\begin{array}{l}\text { 2. Prevenir una posible amenaza a la imagen } \\
\text { del otro (salvaguardar yo-tú) }\end{array}$ & 15 \\
\hline 3. Reparar una amenaza a la imagen del otro & 1 \\
\hline Total & 102 \\
\hline
\end{tabular}

Tabla 3.Función general del atenuante en el discurso

(3)

¿Y qué pasa? ¿Regresa como alcalde?

P3: Es lo más seguro / no sé si haya regresado / nada más pidió licencia

Corpus Es.Var.Atenuación-Monterrey, muestra 4

(4)

1.

¿Quién está jugando? Es la Uefa Ah es Arge contra- ¿contra quién?

P3: Real Madrid

P1: Está el Chicharito / lo concentraron al Chicharito

P3: ¿Ah sí?

P1: Mmm bueno lo concentraron / no sé si lo van a a poner a jugar

Corpus Es.Var.Atenuación-Monterrey, muestra 10 
(5)

P1: No si / sí contesté / pero no sé si se movió solo o con toda la familia

Corpus Es.Var.Atenuación-Monterrey, muestra 29

(6)

P1: ¿Película qué?

P2: Rosa

P1: ¿Rosa? O sea tú le ves romance

P2: Sí

P1: O sea no lo he leído / no te estoy cuestionando / no sé

Corpus Es.Var.Atenuación-Monterrey, muestra 79

\subsection{Tácticas lingüísticas de atenuación}

Se inició con el empleo de verbos, construcciones verbales, y partículas discursivas con valor modal que expresan opiniones en forma de duda o probabilidad. Se encuentra así, que el no sé fungía en su mayoría como partícula discursiva para expresar las opiniones en forma de duda o probabilidad, y en el resto de los casos, no se encontraron verbos, partículas ni construcciones que expresaran las opiniones en forma de duda o probabilidad.

\begin{tabular}{|l|l|}
\hline $\begin{array}{l}\text { 0. No verbos, partículas y construcciones que expresan opiniones } \\
\text { en forma de duda o probabilidad }\end{array}$ & 81 \\
\hline $\begin{array}{l}\text { 2. Partículas discursivas que expresan opiniones en forma de } \\
\text { duda o probabilidad }\end{array}$ & 21 \\
\hline Total & 102 \\
\hline
\end{tabular}

Tabla 4. Tácticas lingüísticas de atenuación

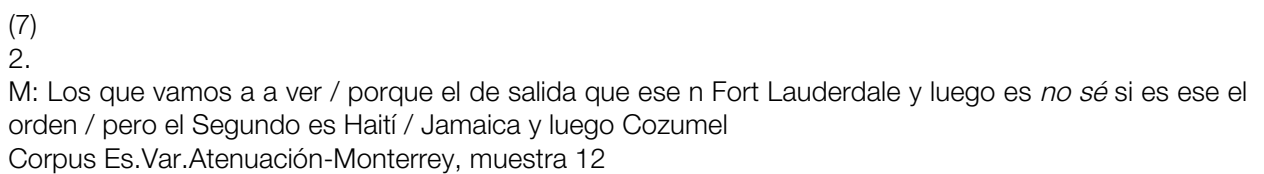

\subsection{El empleo de verbos, construcciones verbales y partículas discursivas}

En su mayoría las partículas expresan fingimiento de ignorancia, o de incertidumbre, de incompetencia sobre la capacidad de una persona para realizar algo. Así también como partículas discursivas que expresan fingimiento de ignorancia o de incertidumbre, de incompetencia.

\begin{tabular}{|l|l|}
\hline $\begin{array}{l}\text { O. No verbos, partículas discursivas y construcciones verbales que } \\
\text { expresan fingimiento de incertidumbre, incompetencia o } \\
\text { ignorancia. }\end{array}$ & 21 \\
\hline $\begin{array}{l}\text { 2. Partículas discursivas que expresan fingimiento de } \\
\text { Incertidumbre, incompetencia o ignorancia. }\end{array}$ & 81 \\
\hline Total & 102 \\
\hline
\end{tabular}


Tabla 5. El empleo de verbos, construcciones verbales y partículas discursivas

(8)

- ya sabes cómo se hacen los juegos y sus menjurjes ahí las empresas para pagar lo menos posible / un cuatro por ciento y a mí / a mí me pegó te lo juro no sé cómo no lloré ahí de de frustración

Corpus Es.Var.Atenuación-Monterrey, muestra 19

\subsection{Reformulación}

Se pudo encontrar que en algunas ocasiones el no sé es utilizado como un movimiento de reformulación a partir del acto propio del hablante, con lo que trata de matizar o corregir lo dicho.

\begin{tabular}{|l|c|}
\hline $\begin{array}{l}\text { O. No movimiento de reformulación } \\
\text { 1. Reformulación con partícula }\end{array}$ & 95 \\
\hline 3. Cambio de tópico & 1 \\
\hline Total & 102 \\
\hline
\end{tabular}

Tabla 6. Reformulación

(9)

1.

P1: (14") En la mañana dieron una- una noticia de Washington / no sé si Washington State o D.C. / Creo que era en D.C. / iban a raptar a una niña de veintidós meses

Corpus Es.Var.Atenuación-Monterrey, muestra 59

(10)

3

P?: No sé si guste salsa o aderezo / jalapeño

P1: ¿Qué aderezo?

P?: Tengo blue cheese / ranch / buffalo / chipotle

Corpus Es.Var.Atenuación-Monterrey, muestra 66

\subsection{Contenido de lo dicho en relación con la imagen}

El contenido de lo dicho, se atenúa, aunque éste no tenga relación con la imagen de los hablantes, ya sea que se trate de un contenido negativo para alguno de ellos, o un participante que no esté presente en la interacción en ese momento, o bien cuando el contenido es positivo o halagador.

\begin{tabular}{|l|l|}
\hline $\begin{array}{l}\text { O. Atenuación de un contenido en el que no están involucradas las } \\
\text { imágenes de ambos }\end{array}$ & 85 \\
\hline 1. Atenuación de un contenido negativo para algún interlocutor & 8 \\
\hline $\begin{array}{l}\text { 2. Atenuación de un contenido negativo para un interlocutor o } \\
\text { institución que no está presente }\end{array}$ & 7 \\
\hline 3. Atenuación de un contenido positivo, con consecuencias positivas & 2 \\
\hline
\end{tabular}

Normas (ISSN: 2174-7245) | 


\begin{tabular}{|l|l|}
\hline Total & 102 \\
\hline
\end{tabular}

Tabla 7. Contenido de lo dicho en relación con la imagen

(11)

P2: ¿Ahí viene ya el del retorno o todavía no? / ¿Qué? / ¿Ahí ya viene el del retorno?

P1: Ah no sé vamos a ver

Corpus Es.Var.Atenuación-Monterrey, muestra 9

(12)

- yo el problema de esos es que no sé tú pero yo me fijo mucho en los sistemas operativos que usas

Corpus Es.Var.Atenuación-Monterrey, muestra 35

(13)

1.

P3: Está haciendo sidra güe / sidra ahí en su casa (0)

P2: ((Mírala))

P3: Sí / no sé / como que andan ahí / pues más o menos bien

Corpus Es.Var.Atenuación-Monterrey, muestra 45

(14)

0.

P2: ¿Maestro de qué? [Mi mamá es educadora yo no sé cómo le hacía

Corpus Es.Var.Atenuación-Monterrey, muestra 39

\subsection{La fuerza ilocutiva del acto de habla}

Se maneja como asertivo, ya sea como expresiones, o las descripciones del estado factual de la realidad, o expresivo, mostrándose inconforme, o quejándose, pero siempre con el fin de mantener la interrelación social, como se había mencionado previamente, sólo por mantener la charla per se. A esto se le identifica como: hablar por hablar.

\begin{tabular}{|l|l|}
\hline $\begin{array}{l}\text { 3. Asertivo/informaciones, expresiones, descripciones del estado } \\
\text { factual de la realidad. }\end{array}$ & 23 \\
\hline 5. Expresivo/insultos, recriminaciones, quejas. & 11 \\
\hline 7. Otros & 68 \\
\hline Total & 102 \\
\hline
\end{tabular}

Tabla 8. La fuerza ilocutiva del acto de habla

(15)

3.

-nos vamos el dieciocho en la tarde lo bueno es que es en la tarde y que son directo los vuelos entonces yo no sé cómo encontraste vuelo (entre risas) estuvo muy bien

Corpus Es.Var.Atenuación-Monterrey, muestra 17

(16)

P3: Porque sin horario comes a la hora que te dé tu gana

P1: Sí porque a ellas no se lo pusieron

M: Si no sé por qué noo

Corpus Es.Var.Atenuación-Monterrey, muestra 15

Normas (ISSN: 2174-7245) |

https://ojs.uv.es/index.php/normas/index

Junio 2017 | Volumen 7 | Número 1| Pág.85 
(17)

7.

P3: Era Adolf Eichmann y él era el que llevaba la logística de Auschwitz (13") Hannah Arendt ella era

P1: No sé quién sea

Corpus Es.Var.Atenuación-Monterrey, muestra 56

Actualmente se cuentan con 14 gráficos de los cuales se han tomado estas muestras y que marcan las tendencias estadísticas de las 102 manifestaciones del no sé en las entrevistas que hasta ahora han sido revisadas.

\section{CONCLUSIONES GENERALES}

A pesar de que no se han establecido hipótesis por comprobar en este primer recuento de apariciones de no sé en conversaciones informales, los resultados incipientes conducen a la posibilidad y tal vez necesidad de realizar algunas predicciones que se basen en algún factor externo a las conversaciones y que no se haya previsto, como puede ser la recurrencia de marcadores atenuantes circundantes a los que se han analizado. No se ha dado énfasis suficiente a la carga significativa proposicional, lo que puede afectar la intención ilocutiva de los hablantes. La modalidad discursiva es otro factor que puede contribuir a la descripción de la modalidad epistémica que está presente en este corpus, en esta fase.

Así mismo, se ha de considerar la alternativa de atenuante de la frase al combinarse con el uso de ésta como señal de ignorancia real, y cuándo se emplea con otros objetivos o intensiones. Existen otras alternativas y acercamientos de empleo de esta frase, lo que hace posible que esta investigación continúe para otros análisis discursivos de estos casos en otra(s) fase(s). Cabe mencionar que se trata de un estudio analítico-descriptivo aún en proceso y, por lo tanto, todavía no se discuten ningún tipo de conclusiones decisivas finales. Debido a esto último, quedan por realizar:

1. Concluir con la ficha del Anexo 3 para obtener nuevos datos para la siguiente fase.

2. La aplicación de la plantilla que sirve de base para esta investigación del no sé a las entrevistas del corpus Monterrey-PRESEEA bajo los mismos parámetros, pero con énfasis en las similitudes y diferencias que se encuentren como una aproximación analítico- descriptiva en los corpus.

3. Una comparación y contraste entre una selección de las entrevistas del corpus Monterrey-PRESEEA con una muestra mayor de las conversaciones de ES.VAR.ATENUACIÓN-Monterrey en la que se muestren concordancias del empleo de no sé por forma y función de acuerdo con los mismos rangos de edad y escolaridad.

4. La búsqueda de otras unidades léxicas atenuadoras que coincidan entre los dos corpus (corpora), por ejemplo, el pero circundante a las frases con no sé + pero, o 
bien, pero no sé, que se ha observado en algunas de las muestras recogidas para este corpus.

\section{BIBLIOGRAFÍA BÁSICA REFERIDA}

Aijmer, Karin. 2002. English Discourse particles; evidence from a corpus. Acta Lingüística

Hefniensia: International Journal of Linguistics 10, Amsterdam: John Benjamins.

www.academia.edu/3207238/Karin Aijmer.2002. Engl ish discourse particles.Evidence from a corpus. Studies in Corpus Linguistics 10. Amsterdam John Benjamins

Albelda M., Marta (2004): "La escalaridad en la intensificación”, en Interlingüística, 15, pp. 105114.

Albelda, M. y Briz, A. (2010). Aspectos pragmáticos. Cortesía y atenuantes verbales en las dos orillas a través de muestras orales. En La lengua española en América. Normas y usos actuales (pp. 237-260). Valencia: Tirant lo Blanch.

Albelda, M., y Cestero, A. M. (2010). "PRESEEA Atenuación. Ficha para Codificación".

Albelda, M., y Cestero, A. M. (2011). De nuevo, sobre los procedimientos de atenuación lingüística. Español Actual, 96, 9-40.

Albelda, M., Briz, A., Cestero, A. M. (2014). "Guía de Estudios de la atenuación en corpus PRESEEA", en http://preseea.linguas.net/Metodología.aspx

Albelda, M., Briz, A., Cestero, A. M., Kotwica, D., y Villalba, C. (2014). Ficha metodológica para el análisis pragmático de la atenuación en corpus discursivos del español. (ES.POR.ATENUACIÓN). Oralia, 17, pp. 7-62.

Briz, A. (1995). La estrategia atenuadora en la conversación cotidiana española. En El español coloquial. Actas del I Simposio sobre análisis del discurso oral (pp. 103-

122). Almería: Universidad de Almería.

Briz, A. (1998) El español coloquial en la conversación. Esbozo de pragmagramática, Barcelona, Ariel.

Briz, A. (2001 [1998]). El español coloquial en la conversación. Esbozo de pragmagramática. Barcelona: Ariel.

Briz, A. (2005). Eficacia, imagen social e imagen de cortesía. En Bravo, Diana (Ed.), Estudios de la (des)cortesía en español (pp. 53-91). Buenos Aires: Dunken

Briz, A. (2007). Para un análisis semántico, pragmático y sociopragmático de la cortesía atenuadora en España y América. Lingüística Española Actual, 29, pp. 5-40.

Briz, A. (2010). El registro como centro de la variedad situacional. Esbozo de la propuesta del grupo Val.Es.Co. sobre las variedades diafásicas. En Fonte Zaraboso, I. (coord.) y Rodríguez Alfano, L. (coord.) (Eds.), Perspectivas dialógicas en estudios del lenguaje (pp.21-56). México: Editorial de la Universidad Autónoma Metropolitana-Iztapalapa.

Briz, A. (2011a). La atenuación como categoría pragmática. En Actas del VII Congreso Internacional de la Asociación Asiática de Hispanistas. Pekín: Foreign Language Teaching and Research Press.

Briz, A. (2011b). Los juicios orales: un subgénero de lo +formal. En Fant, L.y Harvey, A. (Eds.), El diálogo oral en el mundo hispanohablante. Estudios teóricos y aplicados (pp. 139-162). Madrid/Frankfurt: Iberoamericana/Vervuert.

Briz, A, Albelda, M. (2013) "Una propuesta teórica y metodológica para el análisis de la atenuación lingüística en español y portugués. La base de un proyecto en común (ES.POR.ATENUACIÓN)" $\begin{array}{llll}\text { Onomazein } & 28, & 288 & \end{array}$ http://dx.doi.org/10.7764/onomazein.28.21

Caffi, Claudia. (1999). "On mitigation". Journal of Pragmatics, Vol 31(7). http://dx.doi.org/10.1016/S0378-2166(98)00098-8

Cestero, Ana María y Rodríguez Alfano, Lidia (2014), "Guía de Estudios de la atenuación en corpus PRESEEA", http://preseea.linguas.net/Metodología.aspx

Fraser, Bruce. (1980). "Conversational mitigation". Journal of Pragmatics 4, 341- 350. Elsevier.

Fraser, Bruce. (1990). "Perspectives on politeness". Journal of Pragmatics 14, 219 -236. Elsevier.

González Salinas, A. (2014) "Fase exploratoria del empleo de No sé como marcador discursivo de atenuación en el Grupo 1 del corpus Monterrey PRESEEA". En Flores Treviño, María Eugenia; Infante Bonfiglio, José María. La (des)cortesía en el discurso. Perspectivas interdisciplinarias (imagen, actos de habla y atenuación). $1^{\text {a }}$ Ed. Monterrey-Estocolmo: UANL-EDICE, 2014. 
Haverkate, Henk. (1994). La cortesía verbal. Estudio pragmalingüístico. Gredos: Madrid.

Meyer-Hermann, Reinhard. (1988). "Atenuación e intensificación (análisis pragmático de sus formas y funciones en español hablado)", Anuario de Estudios Filológicos, XI, 275-290.

\section{ANEXO 1. DATOS DE CORRELACIÓN DE LA PLANTILLA DE ATENUACIÓN}

\section{Características que se han detectado}

Aten.: contexto en el que es utilizada la partícula del no sé

1. Función: (Función general del atenuante en el discurso)

0. Autoprotección, velar por sí mismo sin que exista un interés directo de la imagen. (Evitar responsabilidades)

1. Salvaguardar el yo, autoprotección del beneficio del yo.

2. Salvaguardar el yo-tu, poner los medios para que no surja un problema con el interlocutor.

3. Reparar una amenaza a la imagen del otro o una intromisión en el territorio del otro

2.6. Probabil. Duda: (Empleo de verbos, construcciones verbales, así como de partículas discursivas con valor modal que expresan opiniones en forma de duda o probabilidad)

2. Partículas discursivas que expresan las opiniones en forma de duda o probabilidad.

0. No verbos, partículas y construcciones que expresan las opiniones en forma de duda o probabilidad

2.7. Fingir ignorancia: (Empleo de verbos, construcciones verbales y partículas discursivas que expresan fingimiento de incertidumbre, de incompetencia o de ignorancia)

0. No verbos, partículas discursivas y construcciones verbales que expresan fingimiento de incertidumbre, de incompetencia o de ignorancia.

2. Partículas discursivas que expresan fingimiento de incertidumbre, de incompetencia o de ignorancia.

2.16. Reform.: (Movimiento de reformulación)

0. No movimiento de reformulación

1. Reformulación con partícula

3. Cambio de tópico 
3. No. Táctica: (Número de procedimientos de atenuación empleados por acto)

1. Una única táctica

2. Dos tácticas

3. Tres tácticas

4. Posic.: (Posición discursiva del atenuante en el miembro discursivo al que afecta)

2. Posición intermedia, en movimientos de reformulación o rectificación de lo anterior

3. Posición inicial, anterior al segmento discursivo afectado

4. Posición final o posterior al segmento discursivo atenuado

5. Mismo atenuante en varias posiciones

5. Tip. Tex.: (Tipología textual)

0. Intervención o intervenciones fático-expositivas

6. Imág.: (Contenido de lo dicho en relación con las imágenes de las personas)

0. Atenuación de un contenido en el que no están involucradas las imágenes de ambos, hablante $\mathrm{u}$ oyente

1. Atenuación de un contenido negativo para algún interlocutor

2. Atenuación de un contenido negativo para un interlocutor o institución que no está presente

3. Atenuación de un contenido positivo, halagador, realzador o con consecuencias positivas para algún interlocutor

7. F. llocut.: (Fuerza ilocutoria del acto de habla)

3. Asertivo/informaciones, expresiones, descripciones del estado factual de la realidad

5. Expresivo/insultos, recriminaciones, quejas

7. Otros

8. Temát.: (Temática)

0. Tema cotidiano: diario y común en la relación socializadora de la gente

9. Fin: (Fin de la interacción)

0. Interpersonal

10. Marco: (Marco físico)

MS: Marco socializador (casa, bar, calle, etc., y en definitiva, cualquier espacio físico que sea de por sí cotidiano e informal o que se haya convertido en cotidiano y en informal para los hablantes 
11. R. Viv.: (Relación vivencial y saberes compartidos entre los interlocutores)
1. Amigo/s
2. Pariente/s
3. Colegas de trabajo + conocidos
6. Desconocidos (incluye a los recipientes escuchas que se manifiestan con monosílabos o risas)

12. R. Soc/fun: (Relación social y funcional entre interlocutores)

0. Relación social o funcional de igualdad

13. Edad: (Edad del hablante)
1. $20-34$
2. $35-54$
3. $55+$

14. R. Edad: (Relación de edad entre interlocutores)

1. Hablante menor que el oyente

2. Hablante mayor que el oyente

3. Intervalos de edad próximos

15. Sexo: (Sexo del hablante)

O. Mujer

1. Hombre

16. R. Sexo: (Relación de sexo entre interlocutores)

0. Mujer Mujer

1. Mujer Varón

2. Varón Mujer

3. Varón Varón

4. Mujer mixto

5. Varón mixto

17. Instr.: (Nivel de instrucción del hablante)

2. Estudios superiores

18. R. Instr.: (Relación de nivel de instrucción entre los interlocutores)

2. Estudios superiores - estudios superiores 
19. Origen: (Origen y procedencia del hablante)

8. Monterrey

20. Gen. Disc.: (Tipo de actividad comunicativa - Mujer, género discursivo)

0. Conversación

21. L. Habit.: (Lengua habitual del hablante)

0. Castellanohablante (monolingüe y bilingüe pasivo)

1. Bilingüe

22. Reg.: (Registro)

0. + Informal

7 ANEXO 2

Muestra de Plantilla de Atenuación, y de gráficos

(Ver siguiente página) 


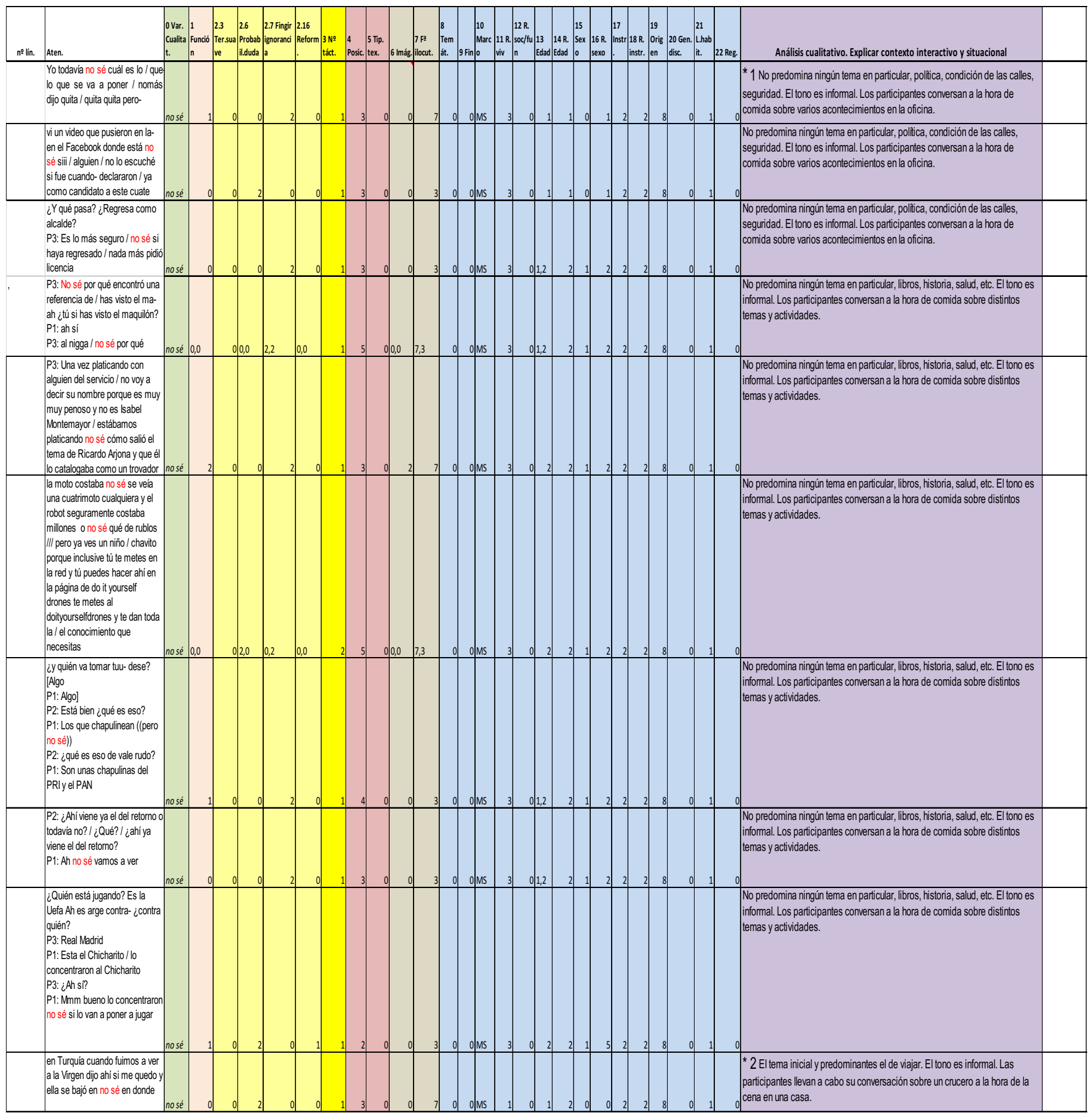

Normas (ISSN: 2174-7245) | 


\section{MUESTRA DE GRÁFICOS (2 DE 16)}

En el primer gráfico se muestra la relación entre el contenido de lo dicho en correspondencia con las imágenes de las personas, se atenúa, aunque este no tenga relación con la imagen de los hablantes.

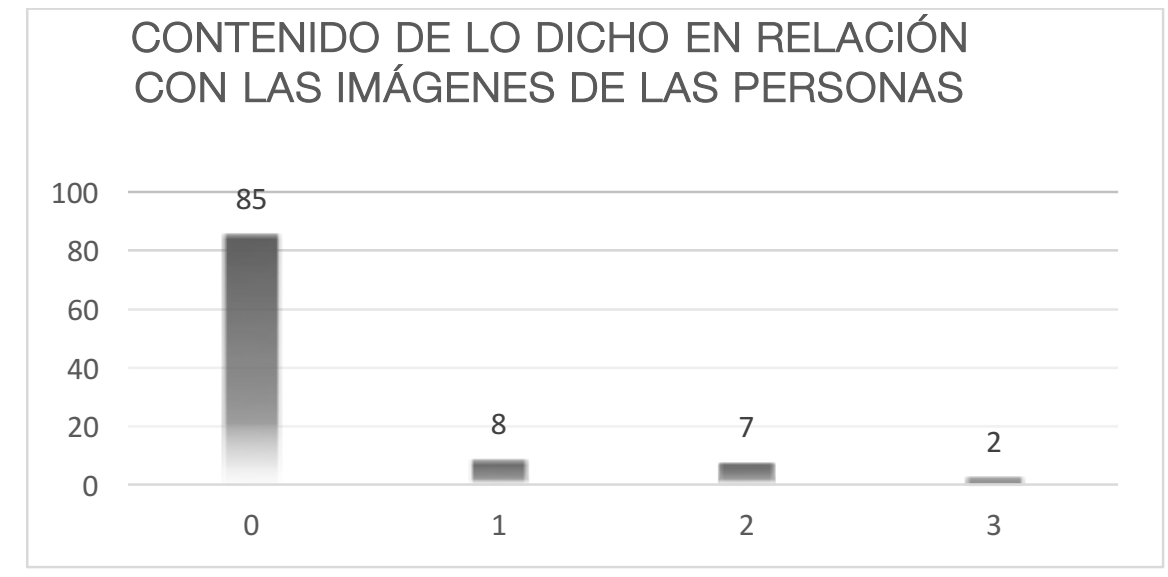

Se presenta el uso de la fuerza ilocutiva del acto de habla como asertivo con el fin del mantenimiento de la interrelación social.

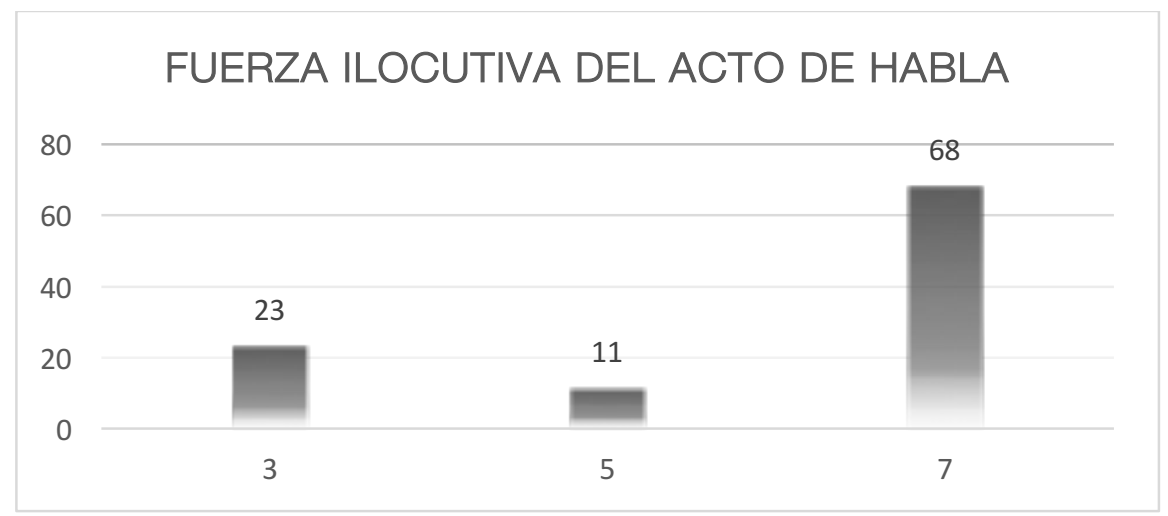

9 ANEXO 3. MUESTRA DE FICHA DE ANÁLISIS DE MUESTRAS DE NO SÉ EN ES.VA.ATENUACIÓNMONTERREY 


\begin{tabular}{|c|c|c|c|c|c|}
\hline \multicolumn{5}{|c|}{ Muestras del empleo de la FRASE LÉXICO-DISCURSIVA "NO SÉ" } & \\
\hline \multirow{9}{*}{$\begin{array}{l}\text { Tema1. No } \\
\text { predomina } \\
\text { ningún tema en } \\
\text { particular, } \\
\text { política, } \\
\text { condición de las } \\
\text { calles, } \\
\text { seguridad. El } \\
\text { tono es informal. } \\
\text { Los } \\
\text { participantes } \\
\text { conversan a la } \\
\text { hora de comida } \\
\text { sobre varios } \\
\text { acontecimientos } \\
\text { en la oficina. }\end{array}$} & & Atenuación & Atenuación y Cortesía & & \\
\hline & \# & $\begin{array}{l}\text { NO SÉ + qué, cómo cuándo } \\
\text { dónde cuál por qué cuanto(a) } \\
\text { cuántos(as) }\end{array}$ & $\begin{array}{l}\text { NO SÉ si + indicativo / } \\
\text { subjuntivo }\end{array}$ & $\begin{array}{l}\text { NO SE } \\
\text { funciones) }\end{array}$ & Análisis \\
\hline & 2 & $\begin{array}{l}\text { Yo todavía no sé cuál es lo / que- } \\
\text { lo que se va a poner / nomás dijo } \\
\text { quita / quita quita pero- }\end{array}$ & & & \\
\hline & 5 & $\begin{array}{l}\text { P3: No sé por qué encontró una } \\
\text { referencia de / has visto el ma- ah } \\
\text { ¿tú si has visto el maquilón? } \\
\text { P1: ah sí } \\
\text { P3: al nigga / no sé por qué }\end{array}$ & & & \\
\hline & 6 & $\begin{array}{l}\text { P3: Una vez platicando con } \\
\text { alguien del servicio / no voy a } \\
\text { decir su nombre porque es muy } \\
\text { muy penoso y no es Isabel } \\
\text { Montemayor / estábamos } \\
\text { platicando no sé cómo salió el } \\
\text { tema de Ricardo Arjona y que él } \\
\text { lo catalogaba como un trovador }\end{array}$ & & & \\
\hline & 7 & $\begin{array}{l}\text { La moto costaba no sé se veía } \\
\text { una cuatrimoto cualquiera y el } \\
\text { robot seguramente costaba } \\
\text { millones o no sé qué de rublos /// } \\
\text { pero ya ves un niño / chavito } \\
\text { porque inclusive tú te metes en la } \\
\text { red y tú puedes hacer ahí en la } \\
\text { página de do it yourself drones te } \\
\text { metes al doityourselfdrones y te } \\
\text { dan toda la / el conocimiento que } \\
\text { necesitas }\end{array}$ & & & \\
\hline & 8 & & & $\begin{array}{l}\text { ¿y quién va tomar } \\
\text { tuu- dese? [Algo } \\
\text { P1: Algo] } \\
\text { P2: Está bien } \\
\text { ¿qué es eso? } \\
\text { P1: Los que } \\
\text { chapulinean } \\
\text { ((pero no sé)) } \\
\text { P2: ¿qué es eso } \\
\text { de vale rudo? } \\
\text { P1: Son unas } \\
\text { chapulinas del } \\
\text { PRI y el PAN }\end{array}$ & \\
\hline & 9 & & & $\begin{array}{l}\text { P2: ¿Ahí viene ya } \\
\text { el del retorno o } \\
\text { todavía no? / } \\
\text { ¿Qué? / ¿ahí ya } \\
\text { viene el del } \\
\text { retorno? } \\
\text { P1: Ah no sé } \\
\text { vamos a ver }\end{array}$ & \\
\hline & 3 & & $\begin{array}{l}\text { vi un video que pusieron } \\
\text { en la- en el Facebook } \\
\text { donde está no sé siil / } \\
\text { alguien / no lo escuché si } \\
\text { fue cuando- declararon / } \\
\text { ya como candidato a } \\
\text { este cuate }\end{array}$ & & \\
\hline
\end{tabular}

Normas (ISSN: 2174-7245) | 


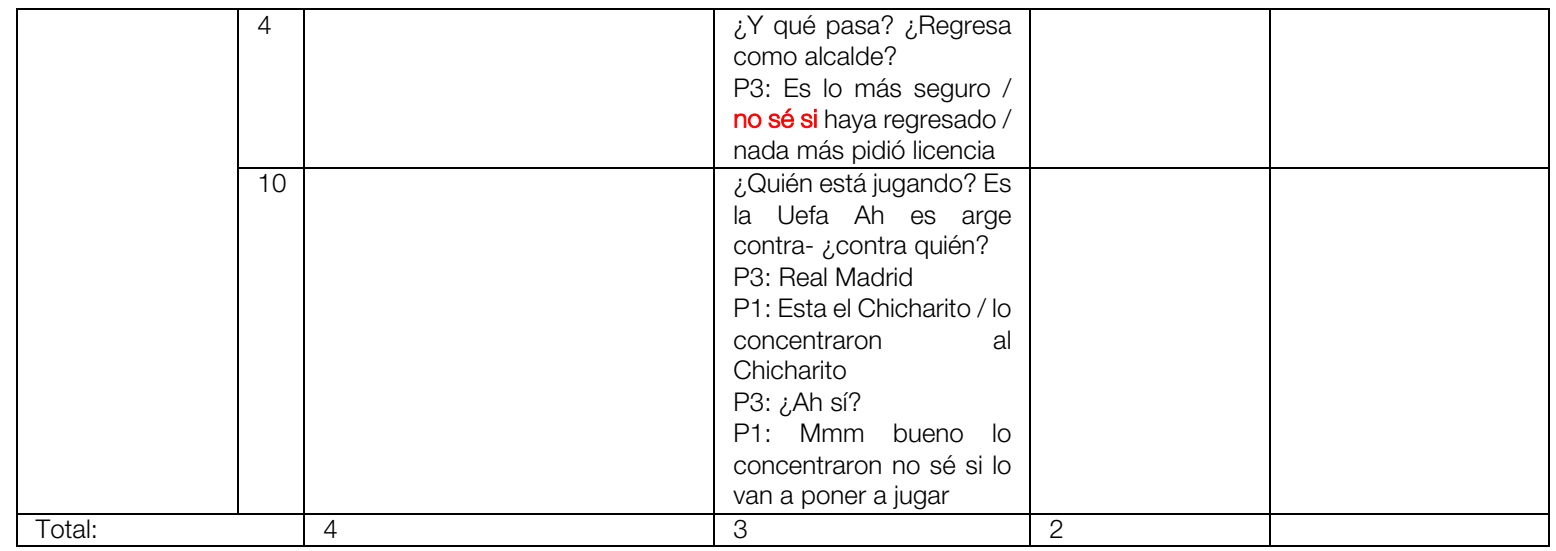


Funciones atenuadoras del conjunto...| Armando González 